\title{
Associations Between Trauma History and Juvenile Sexual Offending
}

\section{Laura EW Leenarts ${ }^{1 *}$, Larkin S McReynolds ${ }^{2}$, Robert RJM Vermeiren ${ }^{3}$, Theo AH Doreleijers ${ }^{4}$ and Gail A Wasserman ${ }^{2}$}

${ }^{1}$ VU University Medical Center, Amsterdam, The Netherlands

${ }^{2}$ Columbia University Medical Center, New York City, USA

${ }^{3}$ Curium University Medical Center, Leiden and VU University Medical Center, Amsterdam, The Netherlands

${ }^{4} \mathrm{VU}$ University Medical Center, Amsterdam and Department of Criminal Justice, Leiden University, The Netherlands

\begin{abstract}
Current study examined the contributions of demographic characteristics, mental health problems and interpersonal trauma history to juvenile sexual offending, and the degree to which juvenile sexual offenders differ from nonsexual interpersonal offenders. Results are based on secondary analysis of a large dataset $(n=2920)$ of psychiatric assessments of juveniles (USA). T-test and chi-square analyses compared demographic, offense, and diagnostic characteristics of juvenile sexual offenders and nonsexual interpersonal offenders. Logistic regression examined the relationship between type of trauma exposure and sex offender status, adjusting for other significant demographic and diagnostic contributors. Results show that compared to juvenile nonsexual interpersonal offenders, sexual offenders were significantly less likely to be female, to be African American, or to meet criteria for a substance use disorder; juvenile sexual offenders were significantly more likely to have a lifetime history of a suicide attempt and a history of sexual victimization. A set of demographic and diagnostic characteristics contributed significantly to juvenile sexual offending, as did self-reported history of sexual trauma. Findings indicate that juvenile sexual offenders in some aspects differ from nonsexual interpersonal offenders; sexual victimization plays an important role in explaining some sexually abusive behavior. Further research should identify interventions that are effective for these youth.
\end{abstract}

Keywords: Psychological assessment; Sexual abuse/assault, Childhood; Logistic regression; Children/Adolescents

\section{Introduction}

Over the past two decades, researchers and clinicians have become increasingly interested in understanding the sexually delinquent behavior of juveniles [1]. Investigations have documented the high rates of histories of interpersonal trauma in juvenile sex offenders [2,3], as well as their high prevalence of mental health problems [4]. Exposure to interpersonal traumatic events is consistently associated with multiple mental health problems for justice system youths, regardless of the presence/absence of a history of sexual offending [5-9].

The higher rates of exposure to interpersonal traumatic events (e.g., sexual and physical abuse) among juvenile sexual offenders compared to juvenile non-sexual offenders [2,3], requires the need to take a closer look at the prevalence of mental health problems in juvenile sexual offenders.

Previous studies comparing juvenile sexual offenders with juvenile nonsexual offenders have shown inconsistent results, or have revealed few differences in rates of mental health problems between those with and without sex offending histories [10-12]. For example, rates of both conduct problems $[12,13]$ and substance use disorders [14] have been found to be lower among juvenile sexual offenders than among juvenile nonsexual offenders. On the other hand, although many sexually abused individuals do not proceed to become offenders themselves [15]; research is consistent regarding both the high prevalence of sexual victimization among sex offenders and the links between these experiences and sexual offending behavior [2].

To an extent, inconsistent results when comparing juvenile sexual and nonsexual offenders may be a consequence of methodological differences among studies (e.g., different types of samples, measurements) and their design limitations, including small sample sizes and the use of non-standardized instruments [11].
We sought to investigate the contributions of demographic characteristics, mental health problems and interpersonal trauma history to juvenile sexual offending, and the degree to which juvenile sexual offenders might differ from juvenile nonsexual interpersonal offenders. Such distinctions would be of clinical relevance in developing offender-specific treatment programs [16]. To address methodological limitations of earlier work, we relied on a large sample of youths from juvenile justice agencies across the United States of America (USA), whose mental health status was assessed on a well-researched computer-assisted self-interview, [Voice Diagnostic Interview Schedule for Children: V-DISC].

\section{Method}

\section{Context}

This investigation relied on a large set $(N=9819)$ of standardized psychiatric assessments resulting from nationwide collaborations with juvenile justice agencies (57 sites in 18 states) in the USA [8,17]. The collaborating agencies represent settings at three levels of increasingly restrictive justice system contact, including system intake sites (e.g., probation or family court intake), detention centers, and postadjudicatory correctional facilities.

*Corresponding author: Laura Leenarts, VU University Medical Center/ de Bascule, PO Box 303, 1115 ZG Duivendrecht, Netherlands, Tel: 003120 8901370/1545; E-mail: I.leenarts@debascule.com

Received September 10, 2013; Accepted October 21, 2013; Published October 23, 2013

Citation: Leenarts LEW, Mc Reynolds LS, Vermeiren RRJM, Doreleijers TAH, Wasserman GA (2013) Associations Between Trauma History and Juvenile Sexual Offending. J Trauma Treat S4: 002. doi:10.4172/2167-1222.S4-002

Copyright: ( 2013 Leenarts LEW, et al. This is an open-access article distributed under the terms of the Creative Commons Attribution License, which permits unrestricted use, distribution, and reproduction in any medium, provided the original author and source are credited. 


\section{Participants}

Altogether 3803 (39\%) juveniles were assessed at system intake, $1055(11 \%)$ at detention intake, and $4961(51 \%)$ at intake into postadjudicatory correctional facilities. For 6798 (69\%) participants, local staff provided information on most serious current offense, utilizing an agreed-on rank ordering of offense seriousness, with sexual offenses designated a priori as the most serious, followed by nonsexual interpersonal offenses, and then by property offenses and substancerelated offenses. Youth with multiple current offenses were coded to the most serious offense. Note that by design, no juveniles considered nonsexual interpersonal offenders were also designated as sexual offenders. For 3021 (31\%) participants, full information on all current offenses was available. We confined analysis to those with current interpersonal offenses $(n=2920)$, comparing those whose current offense was indicated as a sexual offense (e.g., rape) versus a nonsexual interpersonal offense (e.g., aggravated assault). For 387 (4\%), the most serious current offense was a sexual offense, representing offenders from 42 sites in 17 states; for 2533 (26\%) across all settings, the most serious current offense was a nonsexual interpersonal offense. Because sites self-selected themselves for participation, the rate of sexual offenders in this sample is not an estimate of their prevalence among juvenile justice youth overall. Mean age of those with a current interpersonal offense was $15.5(S D=1.6)$; about a quarter of these were female. The majority were African American (40\%) or Caucasian (38\%).

\section{Procedure}

Sites used standardized data collection protocols, assessing the youth shortly after admission via universal or systematic random sampling, measuring a core set of disorders. Sites provided assessment results and de-identified demographic and offense information according to a protocol approved by their Institutional Review Boards.

\section{Measures}

Demographic (gender, age, race/ethnicity) and offense (nature of current offense, number of prior offenses, and age at first offense) characteristics were extracted by local staff from justice records. Following the rank ordering of offense seriousness noted earlier, we designated interpersonal offenders as those whose current offense was a sexual or nonsexual interpersonal offence. Nonsexual interpersonal offenses included assault, robbery, arson, homicide, and all weapons charges. Youths self-assessed their mental health status on the V-DISC (developed by National Institute for Mental Health and Columbia University New York, USA). The V-DISC measures 20 disorders in four clusters: substance use, disruptive behavior, anxiety, and affective disorder, based on past-month symptoms according to the DSM-IV, and utilizes an audio computer-assisted self-interview format; the DISC has been widely used in juvenile justice settings $[18,19]$. The V-DISC's posttraumatic stress disorder (PTSD) module inquires about eight types of traumatic exposure: being in a bad accident or natural disaster, seeing someone get badly hurt, seeing a dead body, being attacked or beaten badly, thinking that you or others would get badly hurt or die, experiencing forced sex or being threatened by a weapon. Of these eight types, following procedures described earlier [8], we considered reports of being attacked or beaten badly, or being threatened by a weapon as reflecting nonsexual trauma victimization. Those who reported exposure to forced sex were considered to be victims of sexual trauma; and those who reported nonsexual trauma and/or sexual trauma were considered as victims of any interpersonal trauma.

\section{Statistical analysis}

First, we compared demographic, offense, and diagnostic characteristics of juvenile sexual offenders and nonsexual interpersonal offenders via t-test and chi-square analyses.

Next, via logistic regression, we examined the relationship between type of traumatic exposure and sex offender status (being juvenile sex offender versus being nonsexual interpersonal offender), adjusting for other significant demographic and diagnostic contributors. From the pool of potential covariates, gender, race/ethnicity, substance use disorder and lifetime history of a suicide attempt were retained in the final equation based on their significant $(p<.02)$ associations with sex offender status in initial bivariate analyses. As we were interested in the contribution of types of interpersonal traumatic exposure to juvenile sex offender status, we constructed three models. The first considered demographic and diagnostic features and reported exposure to any type of interpersonal trauma compared to exposure to non-interpersonal trauma (e.g., being in a bad accident or natural disaster, seeing a dead body). The second model substituted reported exposure to nonsexual trauma for exposure to any interpersonal trauma, and the final model substituted exposure to sexual trauma.

\section{Results}

Table 1 presents demographic, offense and diagnostic characteristics, as well as report of traumatic exposure for juvenile interpersonal offenders, and for sexual and nonsexual interpersonal offenders separately. Compared to juvenile nonsexual interpersonal offenders, sexual offenders were significantly less likely to be female, only 11 of 387 sexual offenders $\left[\chi^{2}(1)=114.28, p<.001\right]$; to be African American $\left[\chi^{2}(3)=94.22, p<.001\right]$, or to meet criteria for a substance use disorder $\left[\chi^{2}(1)=8.57, p<.01\right]$. Juvenile sexual offenders were significantly more likely to report either a lifetime history of a suicide attempt $\left[\chi^{2}(1)=10.80, p<.01\right]$, or exposure to sexual trauma $\left[\chi^{2}(1)=80.45\right.$, $p<.001]$. There were no other significant differences between juvenile sexual offenders and nonsexual interpersonal offenders in age, race/ ethnicity, offense characteristics, or history of exposure to nonsexual trauma or to any interpersonal trauma.

Of the 1367 interpersonal offenders (290 weapon-related, 150 sexual offense, and 927 nonsexual interpersonal offense) for whom complete offense data was available, only $16(1 \%)$ sexual offenders (of 42 sites) had also been charged with nonsexual interpersonal offenses.

Table 2 presents multivariate results predicting sexual offending status, adjusting for demographic and diagnostic characteristics. The first model, considering exposure to either type of interpersonal trauma, significantly predicted sexual offending status $\left[\chi^{2}(7)=223.21\right.$, $\left.p<.001, R^{2}=.17\right]$. Females were less than a tenth $(O R=.08, p<.001)$ as likely as males to be sexual offenders. Compared to African-Americans; Hispanics, Caucasians and other races were more likely to be sexual offenders [Hispanics were approximately 50\% more likely $(O R=1.54$, $p<.05)$, Caucasians were more than three times as likely $(O R=3.27$, $p<.001)$, and the other races were twice as likely $(O R=2.00, p<.05)]$ Compared to juvenile nonsexual interpersonal offenders, sexual offenders were only half as likely to report a substance use disorder $(O R=.54, p<.001)$ but were almost twice as likely to report a lifetime history of a suicide attempt $(O R=1.75, p<.001)$; exposure to any interpersonal trauma was unrelated to sexual offending.

Considering nonsexual trauma, the second model significantly predicted sexual offending status $\left[\chi^{2}(7)=267.00, p<.001, R^{2}=.17\right]$, with contributions of demographic and diagnostic characteristics essentially 
Citation: Leenarts LEW, Mc Reynolds LS, Vermeiren RRJM, Doreleijers TAH, Wasserman GA (2013) Associations Between Trauma History and Juvenile Sexual Offending. J Trauma Treat S4: 002. doi:10.4172/2167-1222.S4-002

Page 3 of 5

\begin{tabular}{|c|c|c|c|}
\hline & Interpersonal offenders $(n=2920)$ & Sexual offenders $(n=387)$ & Nonsexual interpersonal offenders $(n=2533)$ \\
\hline & $n(\%)$ & $n(\%)$ & $n(\%)$ \\
\hline Female $^{\star \star *}$ & $720(24.7)$ & $11(2.8)$ & $709(28.0)$ \\
\hline Age (years, $M, S D$ ) & $15.5(S D 1.6)$ & $15.6(S D 1.7)$ & $15.4(S D 1.6)$ \\
\hline \multicolumn{4}{|l|}{ Race/ethnicity } \\
\hline African American $* * *$ & $1162(39.8)$ & $80(20.7)$ & $1082(42.7)$ \\
\hline Hispanic & $480(16.4)$ & $59(15.2)$ & $421(16.6)$ \\
\hline Caucasian & $1111(38.0)$ & $229(59.2)$ & $882(34.8)$ \\
\hline Other & $167(5.7)$ & $19(4.9)$ & $148(5.8)$ \\
\hline Age at first offense (years, M, SD) & $13.4(2.0)$ & $13.5(2.1)$ & $13.3(2.0)$ \\
\hline Repeat offender & $2049(72.0)$ & $269(73.3)$ & $1780(71.9)$ \\
\hline Substance use disorder ${ }^{* *}$ & $830(30.1)$ & $87(23.6)$ & $743(31.1)$ \\
\hline Lifetime suicide attempt ${ }^{* *}$ & $482(16.9)$ & $87(22.7)$ & $395(16.0)$ \\
\hline \multicolumn{4}{|l|}{ Traumatic exposure } \\
\hline Any interpersonal trauma & $1624(70.7)$ & $237(73.8)$ & $1387(70.2)$ \\
\hline Nonsexual trauma & $1502(52.5)$ & $198(52.0)$ & $1304(52.6)$ \\
\hline Sexual trauma*** & $422(14.8)$ & $114(29.9)$ & $308(12.4)$ \\
\hline
\end{tabular}

Note. Some entries are based on a slightly reduced $\mathrm{n}$ because of missing data.

$M$ : Mean; SD: Standard Deviation

${ }^{* *} \mathrm{p}<.01,{ }^{* * *} \mathrm{p}<.001$.

Table 1: Characteristics of Interpersonal Offenders, and Sexual and Nonsexual Interpersonal Offenders.

\begin{tabular}{|c|c|c|c|c|c|c|}
\hline & \multicolumn{2}{|c|}{ Model $1(n=2205) R^{2}=.17$} & \multicolumn{2}{|c|}{ Model $2(n=2754) R^{2}=.17$} & \multicolumn{2}{|c|}{ Model $3(n=2754) R^{2}=.23$} \\
\hline & OR & $95 \% \mathrm{Cl}$ & OR & $95 \% \mathrm{Cl}$ & OR & $95 \% \mathrm{Cl}$ \\
\hline Female & $.08^{* \star *}$ & {$[.04, .15]$} & $.06^{\star * *}$ & {$[.03, .12]$} & $.04^{\star * *}$ & {$[.02, .08]$} \\
\hline \multicolumn{7}{|c|}{ Race/ethnicity (ref = African American) } \\
\hline Hispanic & $1.54^{*}$ & {$[1.00,2.36]$} & $1.93^{\star *}$ & {$[1.33,2.82]$} & $1.95^{\star \star}$ & {$[1.33,2.86]$} \\
\hline Caucasian & $3.27^{\star \star *}$ & {$[2.39,4.47]$} & $3.37^{* * *}$ & {$[2.53,4.48]$} & $2.96^{* * *}$ & {$[2.21,3.96]$} \\
\hline Other & $2.00^{*}$ & {$[1.11,3.61]$} & $2.10^{*}$ & {$[1.19,3.69]$} & $2.11^{*}$ & {$[1.19,3.75]$} \\
\hline Substance use disorder & $.54^{\star \star *}$ & {$[.40, .72]$} & $.60^{\star \star *}$ & {$[.45, .79]$} & $.63^{\star *}$ & {$[.48, .83]$} \\
\hline Lifetime suicide attempt & $1.75^{\star \star *}$ & {$[1.29,2.39]$} & $1.87^{* * *}$ & {$[1.39,2.52]$} & 1.31 & {$[.96,1.80]$} \\
\hline \multicolumn{7}{|l|}{ Traumatic exposure } \\
\hline Any interpersonal trauma & 1.07 & {$[.80,1.43]$} & - & - & - & - \\
\hline Nonsexual trauma & - & - & .86 & {$[.67,1.09]$} & - & - \\
\hline Sexual trauma & - & - & - & - & $5.02^{* \star \star}$ & {$[3.67,6.87]$} \\
\hline
\end{tabular}

Note. OR: Odds ratio; $\mathrm{Cl}$ :Confidence interval; $R^{2}$ :Nagelkerke $\mathrm{R}$ Square.

${ }^{*} \mathrm{p}<.05,{ }^{* *} \mathrm{p}<.01,{ }^{* * *} \mathrm{p}<.001$.

Table 2: Contributors to Sexual Offending

unchanged, and explaining the same proportion of the variance as found for Model 1. Exposure to nonsexual trauma was unrelated to sexual offending.

The third model, considering exposure to sexual trauma, significantly predicted sexual offending status $\left[\chi^{2}(7)=364.01, p<.001\right.$, $R^{2}=.23$, explaining $6 \%$ more of the variance than did either Model 1 or 2. The contribution of demographic and diagnostic characteristics remained essentially unchanged, except that history of a lifetime suicide attempt no longer contributed significantly to sexual offending status. Compared to juvenile nonsexual interpersonal offenders, sexual offenders were five times as likely to report a history of sexual trauma $(O R=5.02, p<.001)$. When we substituted exposure to both nonsexual and sexual trauma [a total of 300 youths (10\% of interpersonal offenders)], associations for demographic and diagnostic features were consistent with those found earlier, with a contribution of both types of trauma in between that found for Models 2 and $3(O R=3.77, p<.001)$ (data not shown)

\section{Discussion}

This exploratory study aimed to define the degree to which juvenile sexual offenders differed from nonsexual interpersonal offenders as well as the contribution of demographic characteristics, mental health problems and interpersonal trauma history to sexual offending. Compared to juvenile nonsexual interpersonal offenders, sexual offenders were significantly less likely to be female, to be African American, or to meet criteria for a substance use disorder; and were significantly more likely to report a lifetime history of a suicide attempt. These findings are in line with previous reports comparing juvenile sexual and nonsexual offenders [12,14,20,21]. The results concerning the sexual victimization of juvenile sexual offenders are also consistent with earlier findings $[2,22,23]$ that highlight the role of sexual victimization in explaining sexually abusive behavior. However, it should be noted that for those sexual offenders without sexual trauma histories (70.1\%), other factors most likely explain their sexually abusive behavior.

Collectively, the findings suggest that juvenile sexual offenders differ in key aspects from juvenile nonsexual interpersonal offenders. On the other hand, however, consistent with [24], we found sexual offenders were comparable to other offenders in their repeat offender status.

Unexpectedly, there were no differences between the two groups in their age at first offense; van Wijk et al. [24] found violent sexual 
offenders to be younger at first arrest than other violent offenders. Group differences in that study were significant but small, and discrepant results may have been a consequence of differences in the definitions of juvenile sexual and nonsexual offenders across investigations. In the earlier study [24] a juvenile was considered a violent sexual offender when he had committed a violent sex offense first before a possibly violent offense later on, for the group of violent offenders it was the other way around. In the current study we utilized a rank ordering of offense seriousness; with sexual offenses the most serious, followed by nonsexual interpersonal offenses; and juveniles with multiple current offenses were coded to the most serious offense. Also, the finding that only $1 \%$ of the sexual offenders had also been charged with nonsexual interpersonal offenses was remarkable. Whereas it is found that the majority of juvenile sexual offenders also frequently engage in nonsexual interpersonal offenses and antisocial behavior [25]. Such behavior could be explained by the fact that sexual offending is often accompanied by aggressive behavior, for example in case of rape. However, it is also found that most juvenile sexual offenders previously committed a nonsexual assault [25]. It should be noted that this $1 \%$, compared to the other sexual offenders, revealed similar demographic, offense, or diagnostic characteristics. Unfortunately, given the low $\mathrm{n}$ of this group (16), comparisons lacked statistical power to test for significant differences.

A set of demographic and diagnostic characteristics contributed significantly to sexual offending, as did a reported history of sexual trauma. The finding that a history of a lifetime suicide attempt no longer contributed significantly to sexual offending status when we considered exposure to sexual trauma may reflect a power problem, as this concerned only 87 (3\%) observations.

A number of shortcomings of the current study should be mentioned. The current study did not take into account heterogeneity among sexual offenders. Some prior studies have attempted to classify subgroups of juvenile sexual offenders (in e.g., those who victimize children versus those who victimize peers; those who commit sexual and nonsexual offenses versus those who commit only sexual offenses) and to describe differences between subgroups [26-28]. Subgroup analysis, however, has often led to inconsistent findings, with respect to sexual recidivism, social skills, and engagement in nonsexual offending [28]. Therefore, efforts will be needed to validate any such classification of subgroups of juvenile sexual offenders. Perhaps further study which takes into account relevant subgroups will more precisely delineate issues for youth who sexually offend and will have implications for the development of offender-specific interventions and risk prediction.

Another limitation is that the diagnostic measures and history of traumatic exposure were obtained via self-report. There is an ongoing debate about the use of self-report studies in juvenile justice populations, as youths' memory may limit the information that can be captured [29]. However, self-report is preferred over the use of official records to collect the prevalence of maltreatment in detained youth; as official records seriously underestimate the prevalence of maltreatment, especially in males [30]. In addition, self-report may actually be more accurate for internalizing disorders [31]. Furthermore, interpersonal trauma history was inquired about at intake, so that any victimization that occurred during incarceration (for those participants in secure care) would have been missed. Finally, although sub samples were not selected to be nationally or regionally representative, models accounted for clustering of individuals within setting, allowing adjustment for such jurisdictional differences.

Despite these limitations, the current study suggests ways in which future research might address issues of relevance for clinical practice. Consistent with other research, our results indicate that females are less likely than males to commit a sexual offense and that sexual victimization is related to sexual perpetration [2,24]. Although an extensive body of literature has demonstrated that girls in the juvenile justice system have higher rates of past sexual abuse than their male counterparts [32], there is less information about how the long-term negative consequences of sexual victimization (e.g., mental health problems, disruptive behavior, delinquency) differ across gender. Mechanisms related to these negative consequences should be studied and explored. Furthermore, as it has been demonstrated that juvenile sexual offenders may persist in their sexual offending behaviors if not treated [33], evidence-based interventions are required. However, as clinical trials evaluating specific interventions for juvenile sexual offenders are scarce [34,35], further research is desirable to pinpoint effective interventions for these youth.

\section{Reference}

1. Barbaree HE, Marshall WL, Hudson SM (1993) The juvenile sex offender. New York, NY: Guilford Press

2. Burton DL (2008) An exploratory evaluation of the contribution of personality and childhood sexual victimization to the development of sexually abusive behavior. Sex Abuse 20: 102-115.

3. Seto MC, LalumiÃ re ML (2010) What is so special about male adolescent sexual offending? A review and test of explanations through meta-analysis. Psychol Bull 136: 526-575.

4. Van Wijk AP, Blokland AA, Duits N, Vermeiren R, Harkink J (2007) Relating psychiatric disorders, offender and offence characteristics in a sample of adolescent sex offenders and non-sex offenders. Crim Behav Ment Health 17 $15-30$

5. Abram KM, Teplin LA, Charles DR, Longworth SL, McClelland GM, et al. (2004) Posttraumatic stress disorder and trauma in youth in juvenile detention. Arch Gen Psychiatry 61: 403-410.

6. Kerig PK, Ward RM, Vanderzee KL, Arnzen Moeddel M (2009) Posttraumatic stress as a mediator of the relationship between trauma and mental health problems among juvenile delinquents. J Youth Adolesc 38: 1214-1225.

7. Ruchkin VV, Schwab-Stone M, Koposov R, Vermeiren R, Steiner H (2002) Violence exposure, posttraumatic stress, and personality in juvenile delinquents. J Am Acad Child Adolesc Psychiatry 41: 322-329.

8. Wasserman GA, McReynolds LS (2011) Contributors to traumatic exposure and posttraumatic stress disorder in juvenile justice youths. J Trauma Stress 24: 422-429.

9. Wood J, Foy DW, Layne C, Pynoos R, James CB (2002) An examination of the relationships between violence exposure, posttraumatic stress symptomatology, and delinquent activity: An 'ecopathological' model of delinquent behavior among incarcerated adolescents. Journal of Aggression, Maltreatment and Trauma 6: 127-147.

10. Jacobs WL, Kennedy WA, Meyer JB (1997) Juvenile delinquents: A betweengroup comparison study of sexual and nonsexual offenders. Sexual Abuse: Journal of Research and Treatment 9: 201-217.

11. van Wijk A, Loeber R, Vermeiren R, Pardini D, Bullens R, et al. (2005) Violen juvenile sex offenders compared with violent juvenile nonsex offenders: explorative findings from the Pittsburgh Youth Study. Sex Abuse 17: 333-352.

12. van Wijk A, Vermeiren $R$, Loeber $R$, 't Hart-Kerkhoffs L, Doreleijers $T$, et al. (2006) Juvenile sex offenders compared to non-sex offenders: a review of the literature 1995-2005. Trauma Violence Abuse 7: 227-243

13. Butler SM, Seto MC (2002) Distinguishing two types of adolescent sex offenders. J Am Acad Child Adolesc Psychiatry 41: 83-90.

14. Van Wijk AP, Vreugdenhil C, Bullens RAR (2004) Are juvenile sex offenders different from non-sexoffenders? Proces 5: 205-208

15. Glasser M, Kolvin I, Campbell D, Glasser A, Leitch I, et al. (2001) Cycle of child sexual abuse: links between being a victim and becoming a perpetrator. $\mathrm{Br} J$ Psychiatry 179: 482-494. 
Citation: Leenarts LEW, Mc Reynolds LS, Vermeiren RRJM, Doreleijers TAH, Wasserman GA (2013) Associations Between Trauma History and Juvenile Sexual Offending. J Trauma Treat S4: 002. doi:10.4172/2167-1222.S4-002

Page 5 of 5

16. Mulder E, Vermunt J, Brand E, Bullens R, van Marle H (2012) Recidivism in subgroups of serious juvenile offenders: different profiles, different risks? Crim Behav Ment Health 22: 122-135.

17. Wasserman GA, McReynolds LS, Schwalbe CS, Keating JM, Jones SA (2010) Psychiatric disorder, comorbidity, and suicidal behavior in juvenile justice youth. Criminal Justice and Behavior 37: 1361-1376.

18. Teplin LA, Abram KM, McClelland GM, Dulcan MK, Mericle AA (2002) Psychiatric disorders in youth in juvenile detention. Arch Gen Psychiatry 59: 1133-1143.

19. Wasserman GA, McReynolds LS, Ko SJ, Katz LM, Carpenter JR (2005) Gender differences in psychiatric disorders at juvenile probation intake. Am J Public Health 95: 131-137.

20. Heaton P, Davis RE, HappÃ@ FG (2008) Research note: exceptional absolute pitch perception for spoken words in an able adult with autism. Neuropsychologia 46: 2095-2098.

21. Rantakallio $P$, Myhrman A, Koiranen M (1995) Juvenile offenders, with special reference to sex differences. Soc Psychiatry Psychiatr Epidemiol 30: 113-120.

22. Burton DL, Miller DL, Shill CT (2002) A social learning theory comparison of the sexual victimization of adolescent sexual offenders and nonsexual offending male delinquents. Child Abuse Negl 26: 893-907.

23. Veneziano C, Veneziano L, LeGrand S, Richards L (2004) Neuropsychological executive functions of adolescent sex offenders and nonsex offenders. Percept Mot Skills 98: 661-674.

24. van Wijk AP, Mali BR, Bullens RA, Vermeiren RR (2007) Criminal profiles of violent juvenile sex and violent juvenile non sex offenders: an explorative longitudinal study. J Interpers Violence 22: 1340-1355.

25. Righthand S, Welch C (2001) Juveniles who have sexually offended: A review of the professional literature (office of juvenile justice and delinquency prevention report). Washington, DC: Department of Justice.
26. Chu CM, Thomas SD (2010) Adolescent sexual offenders: the relationship between typology and recidivism. Sex Abuse 22: 218-233.

27. 't Hart-Kerkhoffs LA, Vermeiren RR, Jansen LM, Doreleijers TA (2011) Juvenile group sex offenders: a comparison of group leaders and followers. J Interpers Violence 26: 3-20.

28. Kemper TS, Kistner JA (2010) An evaluation of classification criteria for juvenile sex offenders. Sex Abuse 22: 172-190.

29. Snyder H, Sickmund M (2006) Juvenile offenders and victims: 2006 nationa report. Washington, DC: Office of Juvenile Justice and Delinquency Prevention.

30. Swahn MH, Whitaker DJ, Pippen CB, Leeb RT, Teplin LA, et al. (2006) Concordance between self-reported maltreatment and court records of abuse or neglect among high-risk youths. Am J Public Health 96: 1849-1853.

31. Martin JL, Ford CB, Dyer-Friedman J, Tang J, Huffman LC (2004) Patterns of agreement between parent and child ratings of emotional and behavioral problems in an outpatient clinical setting: when children endorse more problems. J Dev Behav Pediatr 25: 150-155.

32. Goodkind S, Ng I, Sarri RC (2006) The impact of sexual abuse in the lives of young women involved or at risk of involvement with the juvenile justice system. Violence Against Women 12: 456-477.

33. Efta-Breitbach J, Freeman KA (2004) Treatment of juveniles who sexually offend: an overview. J Child Sex Abus 13: 125-138.

34. Reitzel LR, Carbonell JL (2006) The effectiveness of sexual offender treatmen for juveniles as measured by recidivism: a meta-analysis. Sex Abuse 18: 401 421

35. Walker DF, McGovern SK, Poey EL, Otis KE (2004) Treatment effectiveness for male adolescent sexual offenders: a meta-analysis and review. J Child Sex Abus 13: 281-293.
This article was originally published in a special issue, Post Traumatic Stress Disorders handled by Editor(s). Dr. Agius M, University of Cambridge, UK 